\title{
Causal diversity effects in information seeking
}

\author{
Nancy S. Kim And Jennelle E. Yopchick \\ Northeastern University, Boston, Massachusetts \\ AND \\ LEONTIEN DE KWAADSTENIET \\ Radboud University Nijmegen, Nijmegen, The Netherlands
}

\begin{abstract}
When trying to determine the root cause of an observed effect, people may seek out information with which to test a candidate hypothesis. In two studies, we investigated how knowledge of causal structure influences this information-seeking process. Specifically, we asked whether people would choose to test for pieces of evidence that were far apart or close together in the learned causal structure of a disease category. In parallel with findings showing people's tendency to select diverse evidence in argument testing (López, 1995), our participants tested for evidence distantly located within the causal structure. Simultaneously, they rated the probability of occurrence of such diverse evidence as comparatively low. These findings suggest that rather than seeking out information most likely to confirm the hypothesis, people seek out evidence that they believe will most strongly support the hypothesis if present but that they also believe is relatively unlikely to be present (that is, might disconfirm the hypothesis).
\end{abstract}

In everyday life, it is often necessary to try to discover the most likely root cause of a presenting problem. We may want to figure out what is making that grinding noise under the hood of our car, why it is that our friend appears to be extremely upset, or what is causing the sore throat of a child. In some of these cases, we may have a particular candidate hypothesis in mind. For example, a pediatrician attempting to determine the root cause of a child's sore throat may consider strep bacteria as a candidate. This hypothesis may be based on the pediatrician's causal knowledge that strep bacteria can launch numerous changes within the human body, where one potential outcome is a sore throat. To test the hypothesis, the pediatrician may start by seeking out additional information.

Once we have a particular hypothesis in mind, what kinds of features do we prefer to look for first? Previous studies have shown that people find features highly diagnostic of the hypothesized category to be useful in hypothesis testing (e.g., McKenzie, 2006). However, in real life, feature diagnosticities may not always be known in detail, or even at all. In such cases, what kinds of features might be investigated? Again, there are multiple possibilities. For example, people may choose features to investigate on the basis of their causal knowledge (Waldmann, Hagmayer, \& Blaisdell, 2006), memories of salient features from other exemplars recently seen, or particular rules of questioning learned in domain-specific training (e.g., if feature $x$ is observed, then first check whether feature $y$ is also present). The present project focuses on the first of these possibilities: the reasoner's causal knowledge. In particular, we highlight the influence of a type of causal knowledge structure we will refer to as a causal hierarchy.

In a causal hierarchy, a solitary root cause gives rise to multiple causal chains of consequences (see Figure 1). Kim and Keil (2003) found that in a diagnostic task, a patient with two symptoms from diverse causal pathways (e.g., scarring of the skin and pneumonia) was judged as more likely to have the underlying disease/cause (e.g., radiation exposure) than was a patient with two symptoms from the same causal pathway (e.g., yeast infection in the mouth and pneumonia). We have called this general finding a causal diversity effect. In contrast, in a control condition in which participants learned only the four final symptoms of radiation sickness, and not the causal structure information, no systematic preference between patients was shown. Notably, the participants were not told any information about the diagnosticities or base rates of symptoms, and they had no prior training in the domain. Thus, their decisions in the causal knowledge condition were likely based on the causal hierarchical structure of the disease category. This causal diversity effect was also found using artificial disease categories, for which symptom frequencies are truly unknown because they do not exist (Kim \& Keil, 2003).

The goal of the present work was to examine whether people actively seek information about causal diversity when starting the reasoning process, or whether the causal diversity effect is limited to the case in which information about the presence of specific features is already known. This issue speaks to the generalizability of the causal di-

N.S.Kim,n.kim@neu.edu 


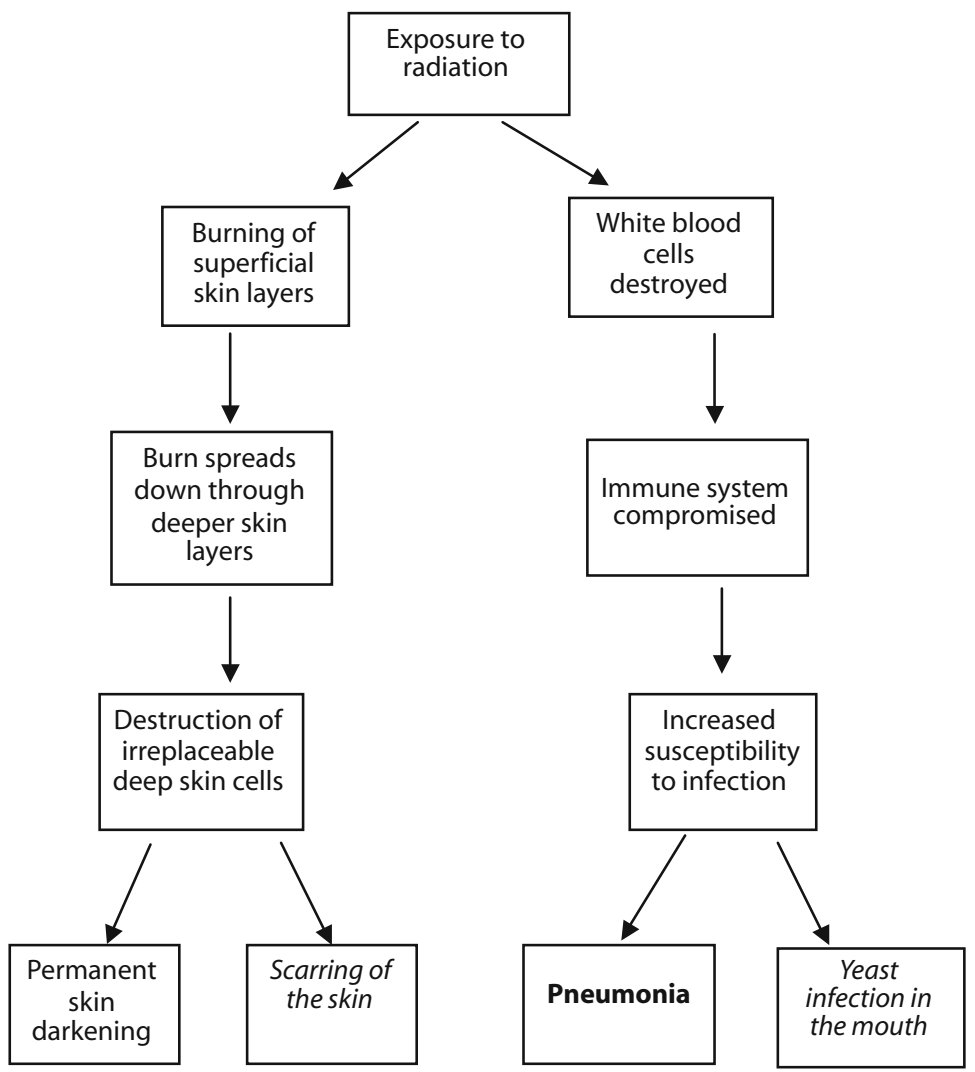

Figure 1. Summary causal diagram of the radiation sickness stimuli used in Study 1. For this medical condition, the participants were told that the patient definitely has pneumonia and were asked to judge whether information about scarring of the skin or a yeast infection in the mouth would be more helpful in determining whether the patient has radiation sickness. In the actual study, normal font (not bold or italicized) was used for all symptoms. Figure adapted from "From symptoms to causes: Diversity effects in diagnostic reasoning," by N. S. Kim and F. C. Keil, 2003, Memory \& Cognition, 31, p. 157. Copyright 2003 by the Psychonomic Society.

versity effect. If people prefer to seek out information about causal diversity, we can more reasonably suppose that the effect may occur even when relevant information is not presented up front. If people do not seek such information, then although previous demonstrations of the causal diversity effect will still stand, the impact of the effect may be considerably less broad.

There are a number of reasons to suspect that people may seek out causally diverse information in reasoning. A series of studies (e.g., López, 1995; Spellman, López, \& Smith, 1999) has shown that people tend to select diverse, as opposed to similar, sets of information to test for when evaluating categorical arguments. For example, López told people that lions had a particular property (e.g., a basilar membrane). When choosing an additional mammal to test when evaluating the hypothesis all mammals have a basilar membrane, people tended to choose a mammal dissimilar to the first. For example, if lion was already known to have the property, people chose to test goat instead of leopard. Picking diverse evidence has previously been argued to be a normative choice, with respect to the philosophical idea that evidence from multiple sources or approaches constitutes stronger support (e.g., Heit, Hahn, \& Feeney, 2005; Popper, 1963; Whewell, 1840/1999) and Bayesian analyses (e.g., Heit, 1998; Horwich, 1982; see, however, Medin, Coley, Storms, \& Hayes, 2003, for arguments about systematic exceptions to the diversity principle). If people adhere to this idea, they may choose to test for causally diverse evidence so that the hypothesis, if confirmed, will be confirmed with the strongest evidence possible.

However, it is also reasonable to suppose that people may choose to seek out causally proximal information. That is, using the example in Figure 1, people told that pneumonia is present might seek information about yeast infection in the mouth when evaluating whether a patient has radiation sickness. Earlier studies (e.g., Wason, 1960) showed that people evaluating a hypothesis often elect to generate and test cases that they most expect to conform to the hypothesis (see Klayman \& Ha, 1987). Tasks in which base rates and conditional probabilities of symptoms were provided yielded similar findings (e.g., Skov \& Sherman, 1986; Slowiaczek, Klayman, Sherman, \& Skov, 1992; but see McKenzie, 2006). To our knowledge, this issue has not previously been examined for hypothesis-testing tasks 
in which information about causal hierarchical structure, but no information about probabilities, is given. Causally proximal information may be expected more to conform to the hypothesis being tested. It is true that both proximal and diverse information, if present, could be said to conform to the hypothesis per se (López, 1995). However, if people think that a causally proximal symptom is more likely to occur than a diverse symptom, choosing to test for a proximal symptom maximizes the chances that the data will conform to the hypothesis, whereas choosing to test for a diverse symptom maximizes the chances that the hypothesis will be disconfirmed. Thus, this contrast may be one of degree.

In sum, in the present studies, we investigated whether people select causally diverse or proximal information to test. In addition, we examined whether people think that a causally proximal symptom is more likely to occur than a causally diverse symptom.

\section{STUDY 1}

\section{Method}

Participants. Eighty Northeastern University undergraduates participated for course credit or payment of $\$ 10 / \mathrm{h}$. Forty participated in the main study, and 40 participated in a manipulation check designed to determine whether the causally proximal symptom was, in fact, more expected than the diverse symptom, as discussed above.

Materials and Procedure. Four medical conditions (allergic reaction, pregnancy, radiation sickness, and Type II diabetes) from Kim and Keil (2003) were used. In Figure 1, the summary diagram for radiation sickness illustrates the basic causal structure of each medical condition, so that a single root cause launched two separate causal chains. Each causal chain contained three intermediate causes and, ultimately, two symptoms. Adjustments were made as needed to fit this causal structure (the stimuli are listed in Appendix A). To prevent the participants from being influenced by visual distance cues, we gave them the causal information for each medical condition as four separate chains. Each chain was labeled with the name of the medical condition. The four diagrams were presented in pseudorandomized order, so that the same causal chain was never seen twice consecutively.

The participants were randomly assigned to one of two groups, causal $(n=20)$ or control $(n=20)$. For each medical condition, causal group participants read the four chains and then wrote a summary of the causal information. Then the participants were told that a patient was definitely experiencing a specific symptom (e.g., pneumonia in Figure 1), hitherto referred to as the presenting symptom. They were asked what additional knowledge about the patient would help most in determining whether the patient had the medical condition. Specifically, the participants chose one out of two symptoms to investigate further. One (the proximal symptom) resulted from the same causal chain as the presenting symptom (e.g., yeast infection in the mouth). The other (the diverse symptom) resulted from the other causal chain in the hierarchical structure (e.g., scarring of the skin). The order of presentation of the two symptoms (proximal and diverse) was randomized for each participant. The four medical conditions themselves were presented in random order.

Control group participants did not see the causal chains or write summary paragraphs. Instead, they learned only the name of the medical condition and its four associated symptoms. The procedure was in all other ways the same as that experienced by the causal group: Given the presenting symptom, the participants chose to further investigate either the proximal or the diverse symptom.

Manipulation check. A separate group of 40 participants experienced a procedure identical to that in the main study, except that they were instead asked, "what additional symptom would you expect [the patient] to have?" Twenty participants were randomly assigned to the causal group and 20 to the control group.

\section{Results and Discussion}

All data were coded so that a choice of the diverse symptom in each medical condition was coded as " 1 " and the proximal symptom as " 0 ." Analyses were conducted at the $\alpha=.05$ level.

The data were collapsed across the four medical conditions for analysis because the binary data did not meet distributional requirements for ANOVAs. An independentsamples $t$ test conducted on the main study data revealed that the diverse symptom was preferred significantly more frequently by the causal group $(M=66.3 \%, S E=$ $8.9 \%)$ than by the control group $(M=37.5 \%, S E=5.9 \%)$ $\left[t(38)=2.69, p=.011, \eta^{2}=.16\right.$; see Figure 2A]. The results ran in the same direction for all four medical conditions. In a comparison of these results with those for Kim and Keil's (2003) corresponding categorization task, the difference in the percentage of diversity-based responses between the causal and the control groups is comparable across the two studies (28.8\% difference in the present study; 27.2\% difference in Kim \& Keil, 2003, Study 1).

In the manipulation check, the participants in the causal group $(M=8.8 \%, S E=4.5 \%)$ were less likely to expect the diverse symptom to occur than were the participants in the control group $(M=46.3 \%, S E=5.8 \%)[t(38)=5.08$, $p<.001, \eta^{2}=.41$; see Figure 2B]. The results ran in the same direction for all four items. Thus, when people knew the causal information, the symptom from the proximal pathway was rated as more likely to occur.

Together, these findings suggest that people opted for a diversity-based strategy and, in doing so, selected information less expected to conform to the hypothesis. More broadly, these results suggest that the influence of causal diversity is not limited to the final diagnostic decision and may influence what data are selected in the first place to test a hypothesis. However, several outstanding issues, described in the next section, remained to be addressed in Study 2.

\section{STUDY 2}

In Study 2, our primary aims were threefold. First, we needed to more fully control for prior knowledge. Study 1 had some level of ecological validity in that real-life stimuli were used, but using artificial stimuli would allow more control over prior knowledge (e.g., symptom base rates). Thus, we used realistic artificial diseases in the present study. Second, Study 1 showed that the causal diversity effect occurs in the information-seeking process, testing the case in which one piece of evidence is already present. However, in some equally realistic diagnostic situations, the reasoner may begin without any evidence. This scenario was implemented in Study 2. The participants were asked to choose between two tests to run on the patient, each of which would provide information about exactly two symptoms. Finally, Study 1 incorporated a forced choice paradigm, which could have artificially strengthened people's apparent preference for diversity. Therefore, in Study 2, we used rating scales. 
A

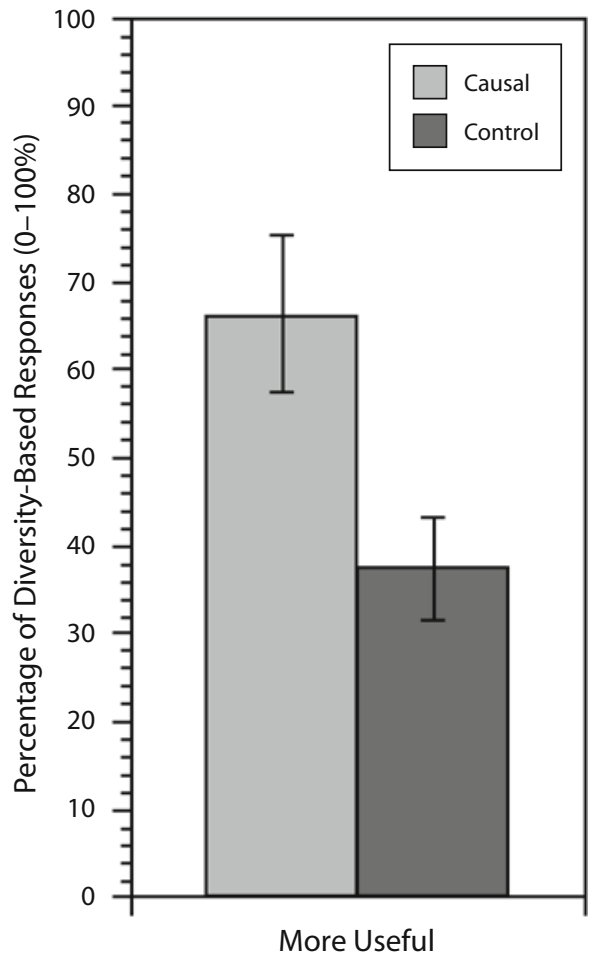

B

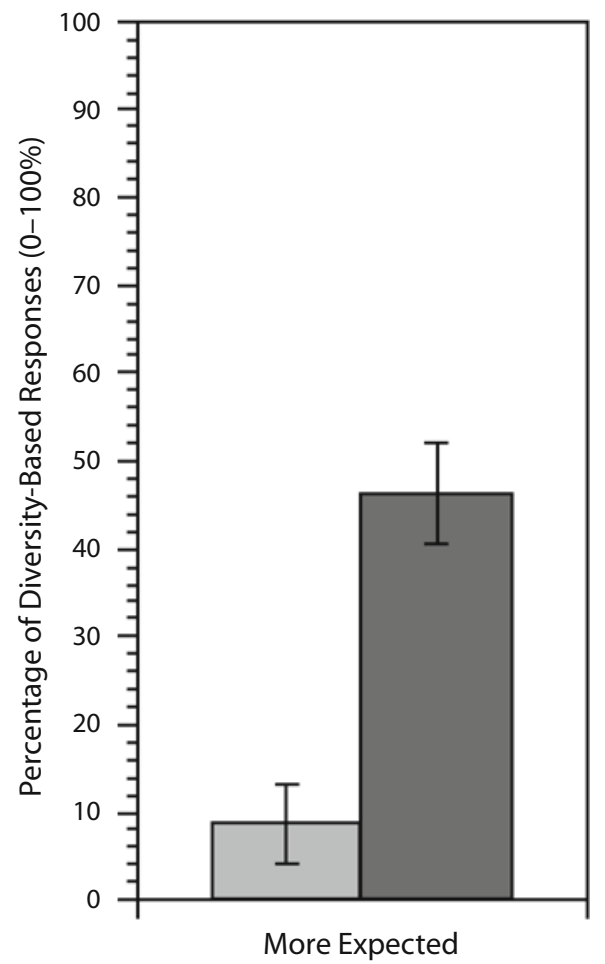

Figure 2. Results of Study 1. (A) Main study. (B) Manipulation check.

\section{Method}

Participants. Forty Northeastern University undergraduates participated for introductory psychology credit or payment of $\$ 10 / \mathrm{h}$. Twenty participated in the main study, and 20 participated in a manipulation check, again designed to document whether the causally proximal symptom was expected more than the diverse symptom.

Materials and Procedure. We used three artificial diseases, described as pathologies of the brain, liver, and bone marrow, respectively (Figure 3 depicts an example; see also Appendix B for a full listing of the remaining stimuli). As in Study 1, the participants viewed the causal information for each disease as four causal chains shown on separate pages. Four-step causal chains were used, instead of five-step chains as in Study 1. Because the diseases in Study 2 were artificial, we reasoned that shorter chains would be easier for the participants to learn.

For each disease, after learning the causal information, the participants took on the role of a physician. They were asked to suppose that a patient came to them for a second opinion regarding another doctor's hypothesis that the patient has disease $X$. The participants learned that two lab tests could be run, but that the patient's insurance would cover only one, and that the tests were equally noninvasive and would yield results equally quickly. One would test only for the presence or absence of two proximal symptoms (providing no information about the remaining two symptoms). The other would test only for the presence or absence of two diverse symptoms. For each test, the participants answered the question, "How informative will this test be in helping you to determine whether or not the patient has [disease X]?" on a scale of 0 to $100(0=$ not at all useful, $100=$ extremely useful $)$.

By using realistic artificial diseases, we were able to counterbalance between participants which pair of symptoms was diverse versus proximal. The terminal effect symptoms were hormone, protein, or platelet levels and could be switched between causal chains within a disease while remaining equally plausible. For example, half of the participants learned the causal information in Figure 3. For these participants, picking a test that measured fibrinogen and prothrombin levels would be a diversity-based response, whereas picking a test that measured fibrinogen and albumin levels would be a proximal response. The remaining participants learned a different causal structure, in which prothrombin and albumin had switched positions and, therefore, causal chains, relative to the diagram in Figure 3. Thus, for these participants, preferring the fibrinogenalbumin test would be a diversity-based response, whereas preferring the fibrinogen-prothrombin test would be a proximal response. Because the proximal versus diverse status of symptoms was counterbalanced, a separate noncausal control was not needed, and all the participants were given causal diagrams. The two causal diagram versions for each disease were always presented between subjects, and the presentation order of the two tests (proximal and diverse) was randomized for each participant.

Manipulation check. A separate group of 20 participants read the same scenario. They were then asked for each test, "to what degree do you expect [patient $\mathrm{X}$ ] to show [both symptoms tested by test Y]?" Responses were given on a scale of $0-100$, where $0=d o$ not expect at all and $100=$ definitely expect.

\section{Results}

All analyses were conducted at the $\alpha=.05$ level. A 2 (test: diverse or proximal) $\times 2$ (causal diagram version) $\times$ 3 (disease item) repeated measures ANOVA on the main study data revealed a main effect of test, so that people judged the diverse test $(M=77.8, S E=4.3)$ to be more potentially informative than the proximal test $(M=49.7$, $S E=4.6)\left[F(1,18)=21.13, p<.001, \eta^{2}=.54\right.$; see Figure 4A]. No other effects or interactions neared significance (all $p \mathrm{~s} \geq .31$, all $\eta^{2} \mathrm{~s} \leq .06$ ). The results ran in the same direction for all three diseases. Thus, people tended to prefer diverse information even when symptoms were fully counterbalanced. 


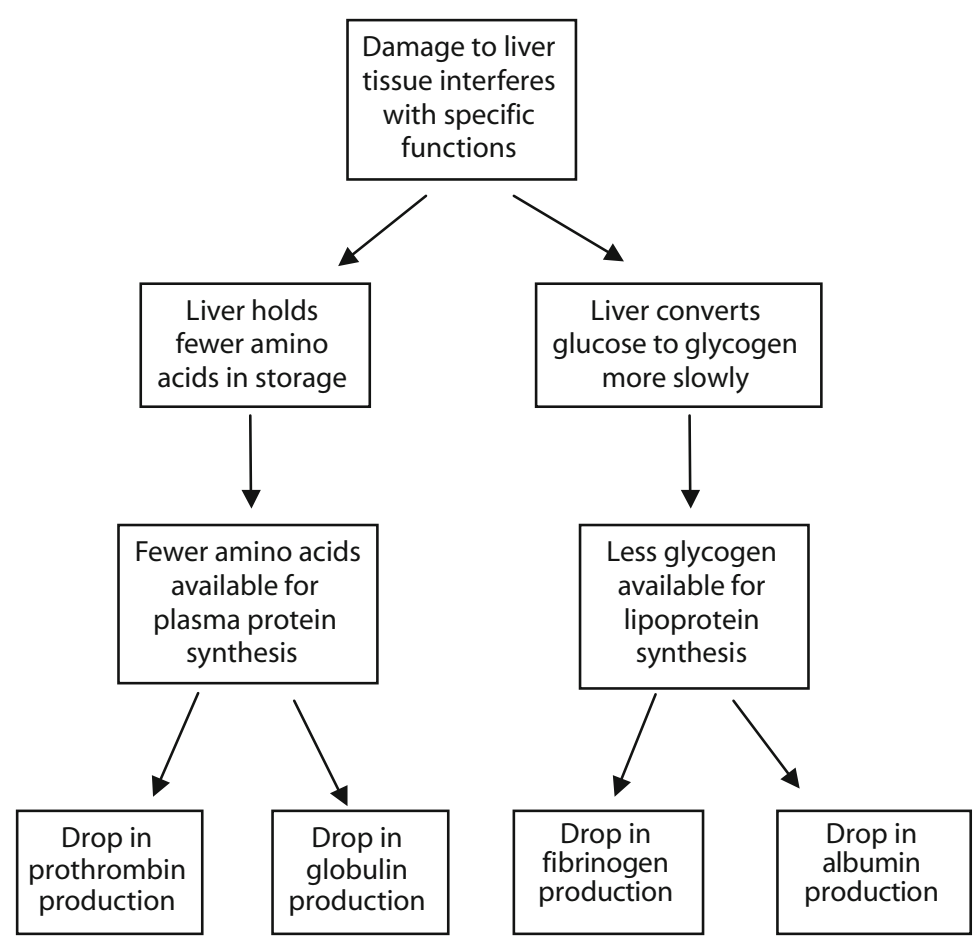

Figure 3. Sample summary causal diagram of the artificial disease stimuli (liver hetroxis) used in Study 2.

Conversely, when asked which pair of symptoms was expected to occur, people rated the proximal pair $(M=68.0$, $S E=5.7)$ as more expected than the diverse pair $(M=$ $54.4, S E=6.3)\left[F(1,18)=4.78, p=.042, \eta^{2}=.21\right.$; see Figure 4B]. This result also ran in the same direction for all three diseases. No other effects or interactions reached significance (all $p \mathrm{~s} \geq .12$, all $\eta^{2} \mathrm{~s} \leq .11$ ). One might observe that these expectedness ratings appear generally higher and closer together than the manipulation check ratings in Study 1. This is likely because, in Study 2, the participants were told that another doctor already thinks that the patient has the disease, leading to greater confidence overall about the presence of all four symptoms.

\section{GENERAL DISCUSSION}

Previous research showed that people are influenced by information about causal diversity in the final diagnosis decision (Kim \& Keil, 2003), but people may not always be given such information in the first place. The present studies showed that people who knew causal hierarchical information preferred to test for causally diverse information. Because diverse symptoms were less expected to occur than proximal symptoms, this selection maximizes the likelihood of disconfirming the root cause hypothesis. However, in the event that the symptoms were found to be present, this choice would also provide the strongest evidence for the hypothesis. This effect was found in real and artificial diseases, using different scenarios and dependent measures. These studies were idealized, in that causal structures were clear and the chains equated for length within each structure and in that diverse and proximal information could be sought with equal ease. Whether diversity would still be sought when structures were more complex remains an open question. Nonetheless, the robustness of the effect suggests that causal diversity is likely to play a role in reasoning.

We suggest that this effect cannot be entirely explained away by a reliance on information about similarity. Study 2 showed that even the exact same symptom pairs were preferred or not preferred in information seeking solely on the basis of their manipulated location in the abstract causal structure. It is also unlikely that the effect could have been driven entirely by associative relations alone, because for the artificial diseases in Study 2, the symptoms had no known base rates or conditional probabilities. However, the causal structure itself might certainly allow people to infer probability information. This possibility builds on McKenzie's (2006) finding that when people know information about the rarity of features, they use that information in diagnostic reasoning. The present studies suggest, in turn, that when people are not directly provided with information about feature rarity, they may infer it from the causal structure.

Why might diverse information be regarded as more useful for diagnosis? One possibility is that people think ahead to what inferences could be made if two causally diverse symptoms were found to be present. If two symptoms from diverse causal chains are present, the simplest, most parsimonious, unifying explanation for both (Read \& Marcus-Newhall, 1993; Thagard, 1992) is that the root cause is present. In contrast, if two symptoms from the same causal chain turn out to be present, the most parsimonious explanation is that the cause immediately pre- 
A

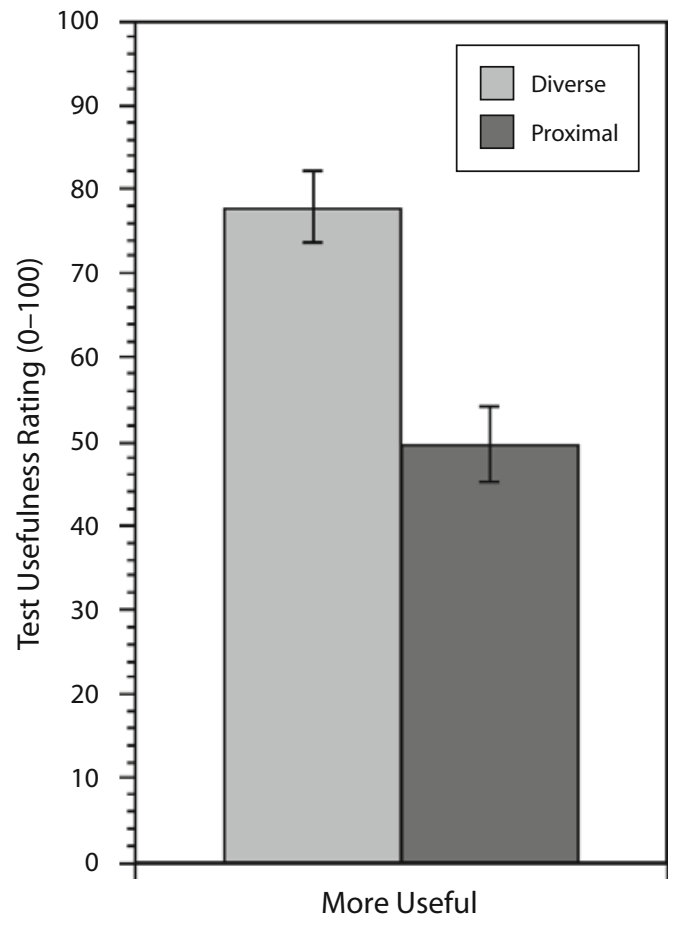

B

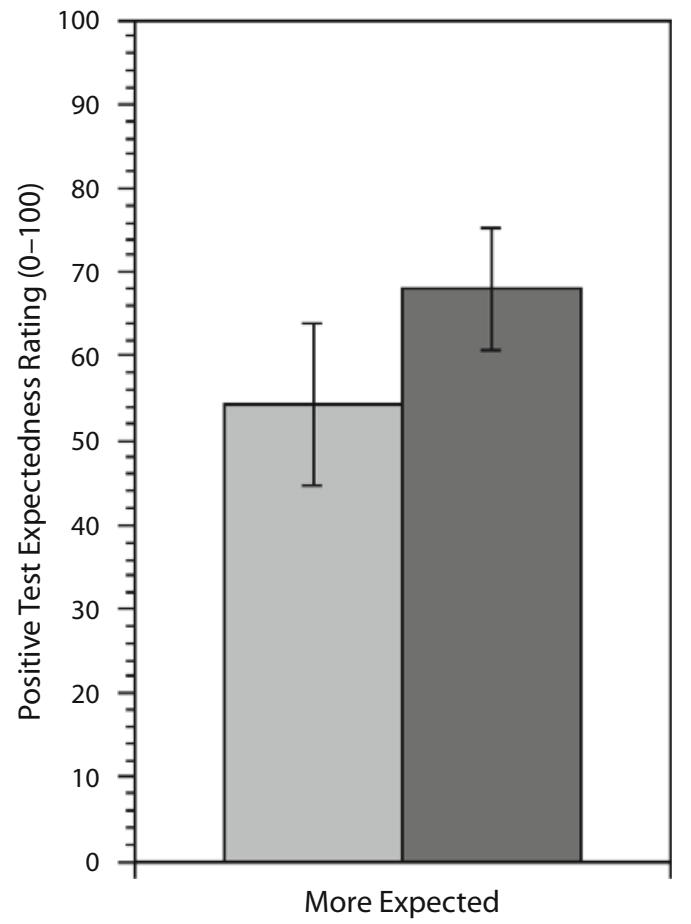

Figure 4. Results of Study 2. (A) Main study. (B) Manipulation check.

ceding the two symptoms is present (e.g., increased susceptibility to infection in Figure 1). This second case could also increase confidence that the root cause is present, but not to the same degree as in the first case.

Second, note again that the corroboration of a hypothesis by diverse lines of evidence has been argued to constitute stronger evidence by some philosophers of science (e.g., Popper, 1963). For example, Whewell (1840/1999) argued that major scientific advances occur when converging support comes from highly different sources. If people intuitively hold this view, they may prefer to seek out diverse evidence in anticipation of building the strongest possible case. Furthermore, as a consequence of having this belief, people might believe that a diverse symptom will better indicate whether alternative root causes should be considered. If the diverse symptom turns out to be present, alternatives may not be considered; if it is absent, this might indicate the need to search for possible alternatives. The proximal choice may be viewed as comparatively less informative in this respect.

Finally, the perceived value of surprising information may have played a role. Our manipulation checks showed that the presence of a diverse symptom would be considered more surprising than the presence of a proximal symptom, and surprising information is generally considered to have more information value in models of learning and in error-correction algorithms (Rescorla \& Wagner, 1972; see also Skov \& Sherman, 1986).

As a final note, future research may determine whether or not this is a domain-general effect. For example, one may have knowledge of causal hierarchical structures for personality traits, so that the hidden trait (the root cause) ultimately gives rise to a variety of observable behaviors. However, it is not yet known whether such structures will also yield causal diversity effects. It may be that in the present studies, the medical domain primed a more scientific mode of thinking in our participants, whereas personality traits may not. Future work might also examine whether the causal diversity effect generalizes to other directed types of structures, such as temporally ordered events (although there may be difficulties in interpretation, in that temporal order can be a strong cue to the perception of causality). These issues remain to be investigated.

\section{AUTHOR NOTE}

We thank Woo-Kyoung Ahn, Lawrence Barsalou, John Coley, Ulrike Hahn, Andrea Patalano, Steven J. Sherman, Barbara Spellman, and Anna Vitkin for helpful comments, Margaret Pierce for help in running experiments, and Katherine Roberts for proofreading the manuscript. Correspondence concerning this article should be addressed to N. S. Kim, Department of Psychology, Northeastern University, 125 Nightingale Hall, 360 Huntington Ave., Boston, MA 02115 (e-mail: n.kim@neu.edu).

\section{REFERENCES}

HeIt, E. (1998). A Bayesian analysis of some forms of inductive reasoning. In M. Oaksford \& N. Chater (Eds.), Rational models of cognition (pp. 248-274). Oxford: Oxford University Press.

Heit, E., Hahn, U., \& Feeney, A. (2005). Defending diversity. In W. Ahn, R. L. Goldstone, B. C. Love, A. B. Markman, \& P. Wolff (Eds.), Categorization inside and outside the laboratory: Essays in honor of Douglas L. Medin (pp. 87-99). Washington, DC: American Psychological Association.

Horwich, P. (1982). Probability and evidence. Cambridge: Cambridge University Press.

KIm, N. S., \& KeIL, F. C. (2003). From symptoms to causes: Diversity effects in diagnostic reasoning. Memory \& Cognition, 31, 155-165. 
Klayman, J., \& Ha, Y.-W. (1987). Confirmation, disconfirmation, and information in hypothesis testing. Psychological Review, 94, 211-228.

López, A. (1995). The diversity principle in the testing of arguments. Memory \& Cognition, 23, 374-382.

McKenzIE, C. R. M. (2006). Increased sensitivity to differentially diagnostic answers using familiar materials: Implications for confirmation bias. Memory \& Cognition, 34, 577-588.

Medin, D. L., Coley, J. D., Storms, G., \& Hayes, B. K. (2003). A relevance theory of induction. Psychonomic Bulletin \& Review, 10, 517-532.

Popper, K. R. (1963). Conjectures and refutations: The growth of scientific knowledge. London: Routledge.

ReAD, S. J., \& Marcus-Newhall, A. (1993). Explanatory coherence in social explanations: A parallel distributed processing account. Journal of Personality \& Social Psychology, 65, 429-447.

Rescorla, R. A., \& Wagner, A. R. (1972). A theory of Pavlovian conditioning: Variations in the effectiveness of reinforcement and nonreinforcement. In A. H. Black \& W. F. Prokasy (Eds.), Classical conditioning II (pp. 64-99). New York: Appleton-Century-Crofts.

SKov, R. B., \& SHERMAN, S. J. (1986). Information-gathering processes:
Diagnosticity, hypothesis-confirmatory strategies, and perceived hypothesis confirmation. Journal of Experimental Social Psychology, 22, 93-121.

Slowiaczek, L. M., Klayman, J., Sherman, S. J., \& Skov, R. B. (1992). Information selection and use in hypothesis testing: What is a good question, and what is a good answer? Memory \& Cognition, 20, 392-405.

Spellman, B. A., López, A., \& Smith, E. E. (1999). Hypothesis testing: Strategy selection for generalising versus limiting hypotheses. Thinking \& Reasoning, 5, 67-91.

Thagard, P. (1992). Conceptual revolutions. Princeton, NJ: Princeton University Press.

Waldmann, M. R., Hagmayer, Y., \& Blaisdell, A. P. (2006). Beyond the information given: Causal models in learning and reasoning. Current Directions in Psychological Science, 15, 307-311.

WASON, P. C. (1960). On the failure to eliminate hypotheses in a conceptual task. Quarterly Journal of Experimental Psychology, 12, 129-140.

WHEWELL, W. (1999). The philosophy of the inductive sciences, founded upon their history. Bristol, U.K.: Thoemmes. (Original work published 1840)

\section{Components of the Medical Stimuli Used in Study 1}

\begin{tabular}{|c|c|c|c|}
\hline \multirow[b]{2}{*}{ Components } & \multicolumn{3}{|c|}{ Medical Condition } \\
\hline & Type II Diabetes & Allergic Emephylgara & Pregnancy \\
\hline Root Cause & $\begin{array}{l}\text { insulin's signal for cells } \\
\text { to take in glucose from } \\
\text { blood is blocked }\end{array}$ & ingestion of allergen & pregnancy \\
\hline Intermediate Causes 1 & $\begin{array}{l}\text { glucose builds up in } \\
\text { blood; glucose pulls water } \\
\text { out of body tissues and } \\
\text { into blood; kidneys sense } \\
\text { excess water in blood and } \\
\text { convert it to urine }\end{array}$ & $\begin{array}{l}\text { allergen absorbed into } \\
\text { blood; allergen causes } \\
\text { irritation of blood vessel } \\
\text { tissue; blood vessel tissue } \\
\text { becomes swollen }\end{array}$ & $\begin{array}{l}\text { increase in progesterone } \\
\text { hormone; progester- } \\
\text { one hormone causes } \\
\text { involuntary muscles to } \\
\text { relax; movement of food } \\
\text { through gastrointestinal } \\
\text { tract is slowed }\end{array}$ \\
\hline Terminal Effects 1 & $\begin{array}{l}\text { increased urination and } \\
\text { increased thirst }\end{array}$ & skin rash and joint pain & nausea and vomiting \\
\hline Intermediate Causes 2 & $\begin{array}{l}\text { very little glucose taken } \\
\text { in by cells; cell energy } \\
\text { input lower than output; } \\
\text { cells seek out alternate } \\
\text { sources of energy }\end{array}$ & $\begin{array}{l}\text { triggers release of hista- } \\
\text { mines; histamines travel } \\
\text { to upper respiratory tract; } \\
\text { triggers secretion of } \\
\text { mucus in nasal passage }\end{array}$ & $\begin{array}{l}\text { change in balance of es- } \\
\text { trogen hormone; triggers } \\
\text { increase in cell salt con- } \\
\text { tent; extra water retained } \\
\text { in cells to balance salt }\end{array}$ \\
\hline Terminal Effects 2 & $\begin{array}{l}\text { loss of body fat and in- } \\
\text { creased appetite }\end{array}$ & $\begin{array}{l}\text { sneezing and nasal } \\
\text { congestion }\end{array}$ & bloating and swollen legs \\
\hline \multicolumn{4}{|l|}{ Patient Symptom } \\
\hline Presenting & loss of body fat & joint pain & nausea \\
\hline Diverse & increased thirst & nasal congestion & bloating \\
\hline Proximal & increased appetite & skin rash & vomiting \\
\hline
\end{tabular}

Note-A fourth medical condition used in Study 2, radiation sickness, is depicted in Figure 1. These stimuli were presented to the participants in diagram format, as described in Studies 1 and 2. A separate control group viewed only the terminal effect symptoms of each medical condition. 
APPENDIX B

Components of the Artificial Disease Stimuli Used in Study 2

\begin{tabular}{|c|c|c|}
\hline Components & Endocrinal Brain Encephalitis & Ellis-Jensen Disease \\
\hline Root Cause & $\begin{array}{l}\text { brain encephalitis causes excess stimula- } \\
\text { tion of certain endocrine tissues }\end{array}$ & $\begin{array}{l}\text { bone marrow produces fewer main stem } \\
\text { cells }\end{array}$ \\
\hline Intermediate Causes 1 & $\begin{array}{l}\text { mucosa of duodenum (endocrine tissue) } \\
\text { is stimulated; alpha-islet cells in the mu- } \\
\text { cosa produce hormones }\end{array}$ & $\begin{array}{l}\text { main stem cells produce fewer myeloid } \\
\text { stem cells; myeloid stem cells manufac- } \\
\text { ture only limited numbers of platelets }\end{array}$ \\
\hline \multicolumn{3}{|l|}{ Terminal Effects 1} \\
\hline $1 \mathrm{a}$ & MSH and ANF hormones secreted & $\begin{array}{l}\text { beta- and kappa-platelet production } \\
\text { drops }\end{array}$ \\
\hline $1 b$ & MSH and CKN hormones secreted & $\begin{array}{l}\text { beta- and gamma-platelet production } \\
\text { drops }\end{array}$ \\
\hline Intermediate Causes 2 & $\begin{array}{l}\text { anterior pituitary (endocrine tissue) is } \\
\text { stimulated; neurosecretory cells in pitu- } \\
\text { itary produce hormones }\end{array}$ & $\begin{array}{l}\text { main stem cells produce fewer lymphoid } \\
\text { stem cells; lymphoid stem cells manu- } \\
\text { facture only limited numbers of platelets }\end{array}$ \\
\hline \multicolumn{3}{|l|}{ Terminal Effects 2} \\
\hline $2 a$ & CKN and THD hormones secreted & $\begin{array}{l}\text { alpha- and gamma-platelet production } \\
\text { drops }\end{array}$ \\
\hline $2 b$ & ANF and THD hormones secreted & $\begin{array}{l}\text { alpha- and kappa-platelet production } \\
\text { drops }\end{array}$ \\
\hline Test I & $\begin{array}{l}\text { tests the levels of MSH and ANF } \\
\text { hormones }\end{array}$ & $\begin{array}{l}\text { tests the levels of beta- and gamma- } \\
\text { platelets }\end{array}$ \\
\hline Test II & $\begin{array}{l}\text { tests the levels of MSH and CKN } \\
\text { hormones }\end{array}$ & $\begin{array}{l}\text { tests the levels of beta- and kappa- } \\
\text { platelets }\end{array}$ \\
\hline
\end{tabular}

Note-A third artificial disease used in Study 2, liver hetroxis, is depicted in Figure 2. These stimuli were presented to the participants in diagram format, as described in Studies 1 and 2. Terminal Effects 1a and 2a were presented to half the participants in Study 2, and Terminal Effects $1 \mathrm{~b}$ and $2 \mathrm{~b}$ were presented to the other half. The order of Patients I and II was counterbalanced between participants.

(Manuscript received May 1, 2007;

revision accepted for publication July 11, 2007.) 